\title{
Utilização da submucosa de intestino delgado porcino como retalho para aumento da capacidade vesical em cães ${ }^{1}$
}

\author{
The use of porcine small intestine submucosa as a graft for urinary bladder augmentation \\ in dogs
}

\author{
Fernando Hintz Greca ${ }^{2}$, Zacarias Alves de Sousa Filho ${ }^{3}$, Antônio de Paula Gomes da Silva ${ }^{4}$, Izabela Soares Leonel ${ }^{5}$, Andréa \\ Thomaz Soccol5, André Nery Feres ${ }^{5}$, Patrícia Longhi ${ }^{5}$ \\ 1. Trabalho realizado na Disciplina de Técnica Operatória e Cirurgia Experimental da Pontifícia Universidade Católica do Paraná. \\ 2. Professor Titular e Coordenador da Disciplina de Técnica Operatória e Cirurgia Experimental da PUCPR. \\ 3. Professor Titular da Disciplina de Técnica Operatória e Cirurgia Experimental da PUCPr. \\ 4. Professor de Patologia Básica na PUCPR. \\ 5. Acadêmica do $6^{\circ}$ ano do curso de medicina da PUCPR, Monitora da Disciplina de Técnica Operatória da PUCPr, bolsista do PIBIC-CNPq. \\ 5 Acadêmica do $5^{\circ}$ ano do curso de medicina da PUCPR, Monitora da da Disciplina de Técnica Operatória da PUCPR. \\ 5. Acadêmico do $5^{\circ}$ ano do curso de medicina da PUCPR, Monitor da Disciplina de Técnica Operatória da PUCPr. \\ 5. Acadêmica do $6^{\circ}$ ano do curso de medicina da PUCPR, Monitora da Disciplina de Técnica Operatória da PUCPr, bolsista do PIBIC-CNPq.
}

\section{RESUMO}

Objetivo: Avaliar a biocompatibilidade de um enxerto xenogênico de SID como meio de ampliação da capacidade vesical. Métodos: Oito cães mestiços foram submetidos à laparotomia e abertura da bexiga por incisão mediana de $3 \mathrm{~cm}$ em sua face ventral. Para aumento da capacidade vesical, bem como sua reconstituição, foi interposto um segmento de submucosa porcina, fixando-o à parede vesical. No $30^{\circ}$ dia de pós-operatório os animais foram sacrificados e procedeu-se à análise macroscópica. As peças foram então encaminhadas para fixação, coloração e análise microscópica. Resultados: Não se observou seroma, hematoma, abscesso, fístula, deiscência, aderências, litíase e a não incorporação do enxerto. Microscopicamente observou-se em todos os casos uma proliferação do urotélio que recobriu toda a superfície do enxerto, além da presença de fibras musculares lisas no local do implante. Verificou-se proliferação conjuntiva, principalmente às custas de colágeno imaturo do tipo III e reação inflamatória crônica em todos os animais. A proliferação vascular foi acentuada e a reabsorção da membrana foram também observadas. Conclusão: Asubmucosa de intestino delgado porcino participou como um substrato para a regeneração da bexiga e pode ser uma futura alternativa na reconstrução do trato urinário.

Descritores: Intestino delgado. Retalhos cirúrgicos. Biopróteses. Bexiga. Cães.

\begin{abstract}
Purpose: To evaluate the biocompability and histological changes of the porcine intestine submucosa (SIS) used for bladder augmentation in dogs. Methods: eight mongrel dogs underwent laparotomy and a $3 \mathrm{~cm}$ full-thickness midline cistotomy was performed in its ventral surface. In order to produce an immediate augmentation of the bladder, a porcine SIS patch graft was implanted. On the 30th post-operative day the animals were submitted to a second operation for a grossly evaluation of the implanted graft. Results: there was no finding of seroma, hematoma, abscess, fistula, adhesion and stone formation. The bladder was then removed for histological studies and the animals were sacrificed. A chronic inflammatory process was observed in all animals. The urothelium covered the implant in $100 \%$ of the cases and smooth muscles fibers were seen in the graft area. The angiogenesis was significant and reabsorption of the implanted submucosa could be observed. The densitometry of collagen showed that the area occupied by immature collagen type III was greater than the area occupied by the mature collagen, type I. Conclusion: SIS can be used as a bladder substitute, since it acts as a scaffold for tissue regeneration.
\end{abstract}

Key words: Intestine, Small. Surgical Flaps. Bioprosthesis. Bladder. Dogs. 


\section{Introdução}

Alternativas para reconstituição do aparelho urinário, especialmente no que concerne a reconstrução vesical, têm sido pesquisadas. Materiais aloplásticos e biodegradáveis têm sido sugeridos, todavia altas taxas de complicações relatadas têm limitado seu uso ${ }^{1}$.

A reconstrução vesical necessita de um material que aumente sua complacência e seu volume, sem no entanto, causar alterações imunológicas no receptor do enxerto.

Pesquisas demonstram que a bexiga urinária tem capacidade natural de auto reparação e remodelação. Atualmente duas técnicas de regeneração e aumento vesical têm sido propostas $^{1,2,3}$. A primeira envolve técnicas de engenharia tecidual, usando materiais biodegradáveis que atuam como veículos transportadores celulares. Esta técnica envolve cultivo e cultura in vitro de células epiteliais. A segunda, fundamentase no desenvolvimento de materiais biodegradáveis, acelulares, autogênicos ou xenogênicos, constituídos de matriz acelular de colágeno.

Vários são os segmentos do trato gastrointestinal que podem ser utilizados na cirurgia urológica. O estômago, o jejuno, o íleo e o cólon apresentam propriedades próprias, as quais resultam em vantagens e desvantagens no seu uso. A escolha do segmento adequado deve ser baseada no estado geral do paciente, na função renal, na história prévia de intervenções cirúrgicas abdominais e no tipo de cirurgia desejada.

O estômago tem sido utilizado para substituição vesical, ampliação da capacidade da bexiga, confecção de condutos e derivações urinárias. As principais vantagens do estômago em relação a outros segmentos são: baixa permeabilidade a solutos urinários, acidificação da urina, excreção de cloretos numa proporção maior que sua absorção, menor produção de muco, baixo índice de aderências e incidência de bacteriúria de $25 \%$. O uso do estômago, todavia, poderá acarretar o aparecimento de anemia ferropriva ou megaloblástica, hipoproteinemia, síndrome do estômago curto, esteatorréia e vômitos incoercíveis.

O íleo é um segmento amplamente utilizado. Na metade do século $\mathrm{XX}{ }^{4,5}$ várias técnicas de ileocistoplastia foram descritas. Dentre as vantagens das ileocistoplastias, podem ser citadas: boa mobilidade, pequeno diâmetro e anatomia vascular constante. Entre as desvantagens, por outro lado, podemos mencionar: a diminuição da absorção de cianocobalaminas, diarréia pela falta de absorção de sais biliares e distúrbios da absorção de gorduras.

A submucosa do intestino delgado é uma membrana xenogênica, acelular, classificada como material biodegradável, obtido do intestino delgado de porco. Após a remoção das demais camadas do intestino, obtém-se um tubo translúcido de aproximadamente $0,1 \mathrm{~mm}$ de espessura e que apresenta propriedades singulares ${ }^{2}$, que permite sua utilização como biomaterial ${ }^{4}$. A submucosa porcina, através de inúmeras pesquisas nas mais diversas áreas da Medicina (Urologia, Gastroenterologia, Dermatologia, Ortopedia, Odontologia, Imunologia, Bioengenharia dos tecidos, Cardiologia) tem-se mostrado versátil e eficiente, pois além de não desencadear respostas antigênicas no receptor, é capaz de funcionar como molde induzindo a regeneração do tecido nativo no qual foi implantada ${ }^{5}$. A fibronectina, proteína que apresenta atividade quimiotáxica e adesiva para diversos tipos de células, incluindo fibroblastos e células endoteliais, compreende aproximadamente $0,1 \%$ do peso da submucosa intestinal, e está distribuída em toda a sua espessura.

Sabe-se que existem proteínas detectáveis na submucosa intestinal, extraídas por técnica $\mathrm{HCl}$-guanitidina ou uréia, que reagem com um anticorpo policlonal anti-fator de crescimento endotelial vascular (VEGF). Ambos extratos de submucosa intestinal são capazes de induzir a formação de estruturas fenestradas semelhantes a capilares em uma matriz tridimensional de fibrina ${ }^{6}$.

Número significante de células endoteliais microvasculares humanas aderem em ambos os lados da submucosa intestinal in vitro. A aderência destas células à submucosa intestinal é maior que a observada nas placas de Petri, e é otimizada quando a submucosa é hidratada ou tratada com ácido paracético (PAA). Placas de Petri cobertas com colágeno I ou IV e fibronectina apresentam maior aderência de células em relação às placas sem esta cobertura, porém a quantidade de células ainda é inferior à submucosa intestinal ${ }^{7}$.

O objetivo do presente estudo foi avaliar o comportamento histológico e funcional do enxerto de submucosa intestinal porcina como meio de ampliação da capacidade vesical em cães.

\section{Métodos}

$\mathrm{Na}$ elaboração deste estudo foram obedecidas as normas do Colégio Brasileiro de Experimentação Animal (COBEA).

Foram utilizados oito cães mestiços, machos, com idade média de 6 anos, com peso variando de 8 a $15 \mathrm{~kg}$, provenientes do Biotério Central da Pontifícia Universidade Católica do Paraná.

Os animais foram mantidos em compartimentos individuais, sob temperatura e luminosidade naturais, recebendo água potável e ração padrão comercial em regime livre. O jejum foi instituído nas 12 horas precedentes às intervenções cirúrgicas.

A indução anestésica foi realizada com o Thiopental a $5 \%$ por via endovenosa. Para a manutenção anestésica, utilizouse o citrato de fentanila na dose de $10 \mu \mathrm{g} / \mathrm{kg}$ e midazolan na dose de $0,2 \mathrm{mg} / \mathrm{kg}$, também por via endovenosa. A anti-sepsia da região operatória foi realizada com polivinilpirrolidona - iodo ativo $1 \%$ (PVPI).

Os animais foram submetidos a laparotomia mediana infra-umbilical, de aproximadamente $8 \mathrm{~cm}$ de extensão. Após a identificação da bexiga e punção da mesma para promover seu esvaziamento, realizou-se uma incisão mediana de $3 \mathrm{~cm}$ na sua face ântero-superior até atingir-se a luz do órgão e em seguida uma incisão de $1 \mathrm{~cm}$ transversalmente, o que resultou num defeito de $3 \mathrm{~cm} \times 1 \mathrm{~cm}$ (Figura 1).

Um segmento duplo de submucosa de intestino delgado, medindo aproximadamente $4 \mathrm{~cm} \times 2 \mathrm{~cm}$, foi implantado na parede da bexiga, com a face da mucosa voltada para a luz 
vesical. Através de sutura contínua, em plano total único com fio de poliguecaprone (Monocryl ${ }^{\circledR}$ ) $n^{\circ} 4.0$ reparou-se o defeito criado. Convém salientar que nenhum dos cães operados permaneceu com sonda vesical de alívio durante o período pósoperatório.

Para a obtenção da SID foi utilizada uma porção de jejuno de suíno proveniente de um abatedouro da cidade de Curitiba. No Laboratório de Técnica Operatória e Cirurgia Experimental da Pontifícia Universidade Católica do Paraná, a porção de jejuno foi exaustivamente lavada com água corrente e em seguida retirado seu mesentério. Essa porção intestinal foi invertida para a expor a mucosa e permitir a remoção da mesma por raspagem com bisturi. Desfeita a inversão do segmento, o extrato seromuscular foi removido pela mesma técnica. A mem- brana foi preservada em solução de sulfato de neomicina a 10\%. No trigésimo dia de pós-operatório foi realizada uma nova laparotomia na qual os cuidados pré-operatórios e anestésicos seguiram as mesmas normas adotadas na primeira operação. Esta segunda laparotomia teve por finalidade avaliar as possíveis complicações da enxertia tais como: seromas, hematomas, fístulas, abscessos, calcificações, aderências, nãoincorporação do enxerto ou deiscência da sutura. Após avaliação dos parâmetros mencionados acima, os animais foram submetidos à eutanásia mediante administração de dose letal de $\mathrm{KCl}$ a $19,1 \%$ por via endovenosa. Após o estudo macroscópico inicial, as peças cirúrgicas contendo o enxerto submucosa intestinal porcina foram imersas numa solução de formaldeído a 5\% para estudo anátomo-patológico.

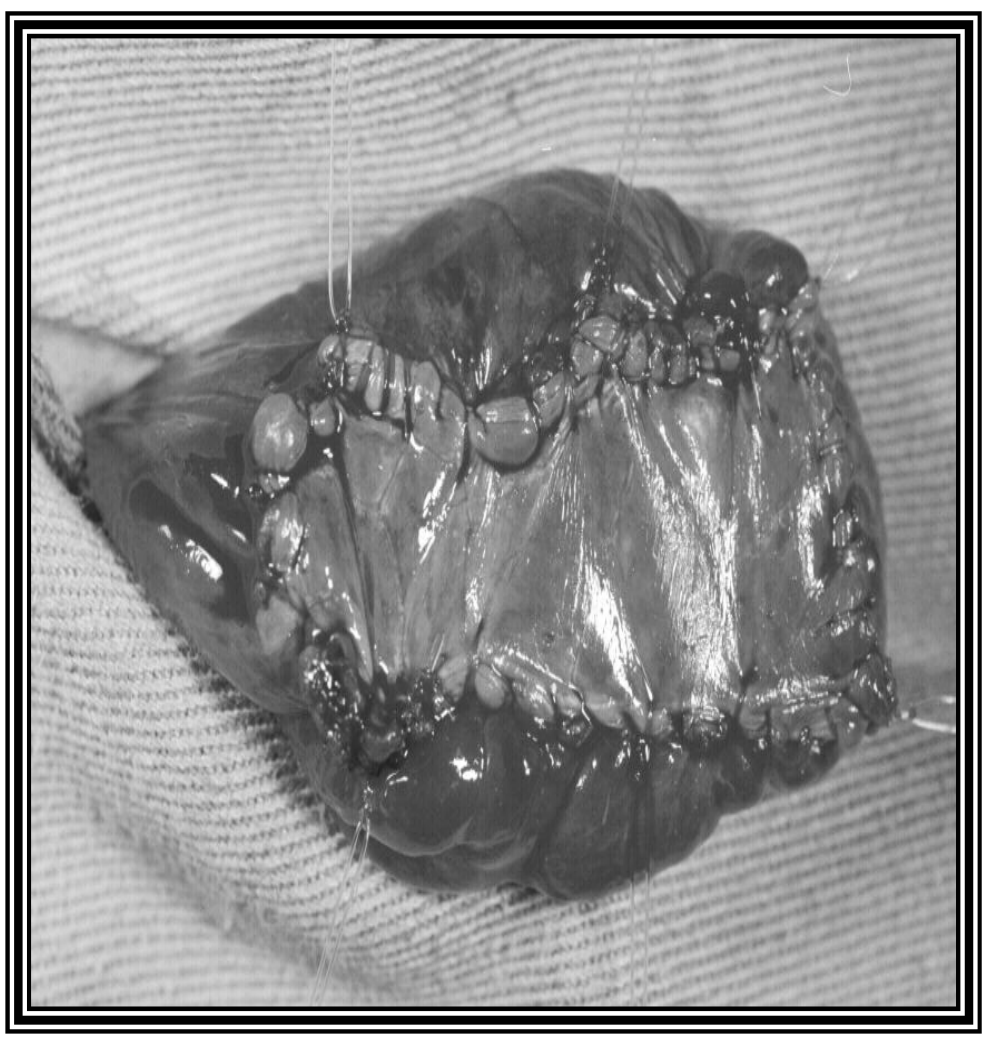

FIGURA 1 - Cistostomia e implante do enxerto duplo de SID

As peças fixadas em formalina a $5 \%$, foram processadas segundo as técnicas histológicas convencionais e então coradas com hematoxilina-eosina, sirius red e tricrômico de Mallory para realização da análise microscópica.

Dividiu-se o estudo em análise subjetiva e em objetiva. $\mathrm{Na}$ análise subjetiva, as lâminas coradas com hematoxilinaeosina foram avaliadas quanto a presença ou a ausência de urotelização, músculo liso, fibrose, tecido de granulação, rejeição e regeneração. A análise objetiva, ainda com a coloração de hematoxilina-eosina, consistiu na quantificação e qualificação do processo inflamatório, utilizando-se de uma tabela objetiva de escores. Para a construção desta tabela foram escolhidas as variáveis congestão, edema e neutrófilos para caracterizar o processo inflamatório agudo. Presença de tecido de granulação, fibrose e células mononucleares foram escolhidas para caracterizar fase inflamatória crônica. Tanto as variáveis da fase inflamatória crônica como da fase aguda foram quantificadas em: ausente (0), discreto (1), moderado (2) e 
acentuado (3), sendo que aquelas da fase aguda receberam sinal negativo e as da fase crônica sinal positivo. A somatória de todas as variáveis permitiu a realização de um escore inflamatório (tabela 1). Os escores situados entre -9 e -2 fo- ram considerados escores inflamatórios da fase aguda; aqueles entre $-1 \mathrm{e}+1$ foram considerados isentos de reação inflamatória e entre +2 e +9 caracterizaram uma fase inflamatória crônica.

TABELA 1 - Variáveis estudadas com o respectivo escore atribuído

\begin{tabular}{lccccc}
\hline $\begin{array}{l}\text { Processo } \\
\text { Inflamatório }\end{array}$ & Variáveis & ausente & discreto & moderado & acentuado \\
\hline \multirow{3}{*}{ Agudo - } & neutrófilos & 0 & -1 & -2 & -3 \\
& edema & 0 & -1 & -2 & -3 \\
& congestão & 0 & -1 & -2 & -3 \\
\hline \multirow{3}{*}{ Crônico +} & monócitos & 0 & 1 & 2 & 3 \\
& tec.granulação & 0 & 1 & 2 & 3 \\
& fibrose & 0 & 1 & 2 & 3 \\
\hline
\end{tabular}

A leitura das lâminas coradas com hematoxilina-eosina e tricrômico de Mallory permitiu a contagem do número de vasos sanguíneos por campo. Foram lidos cinco campos distintos em cada lâmina e foi feita uma graduação comparativa, classificando a proliferação vascular em moderada e intensa.

Além disso, as lâminas coradas com sirius red foram utilizadas para a avaliação quantitativa de colágeno e de tecido muscular presentes no local enxertado. Em cada área (enxerto ou referencial) foram realizadas 6 medidas em 6 campos microscópicos diferentes. Esta avaliação morfométrica utilizou o "software" Image Pro-Plus acoplado a câmara de vídeo Sony e microscópio BX 50, calibrado em aumento para uma objetiva de 100 vezes.

\section{Resultados}

Nenhum dos cães estudados foi a óbito. Na avaliação macroscópica realizada por ocasião do sacrifício, evidenciouse incorporação perfeita de todos os implantes, tornando-os quase indistinguíveis das outras áreas da bexiga. A palpação cuidadosa demonstrou leve espessamento no local do implante. Foram observadas aderências discretas do peritônio parietal no local do enxerto e não foram observadas complicações na área de enxertia tais como: seromas, hematomas, fístulas, abscessos,

calcificações ou deiscência.

\section{Análise microscópica}

\section{Subjetiva:}

A Tabela 2 mostra o percentual de ocorrência dos parâmetros analisados no estudo macroscópico subjetivo.

TABELA 2 - Estudo anátomo-patológico. Percentual de ocorrência dos parâmetros analisados

\begin{tabular}{lll}
\hline & Ausente & Presente \\
\hline Reação tipo granulomatosa & $12,5 \%(\mathrm{n}=1)$ & $87,5 \%(\mathrm{n}=7)$ \\
Urotelização & $0 \%(\mathrm{n}=0)$ & $100 \%(\mathrm{n}=8)$ \\
Neoformação de músculo liso & $0 \%(\mathrm{n}=0)$ & $100 \%(\mathrm{n}=8)$ \\
Regeneração & $0 \%(\mathrm{n}=0)$ & $100 \%(\mathrm{n}=8)$ \\
Rejeição & $100 \%(\mathrm{n}=8)$ & $0 \%(\mathrm{n}=0)$ \\
\hline
\end{tabular}


Análise microscópica

Objetiva:

O processo inflamatório crônico foi encontrado em todas as áreas enxertadas, com infiltrado mononuclear e tecido de granulação, como pode ser observado pela média $(+5)$ das somatórias de todos os parâmetros analisados Os resultados podem ser observados na Tabela 3 .

TABELA 3 - Escores do processo inflamatório no local enxertado

\begin{tabular}{|c|c|c|c|c|c|c|c|}
\hline & Congestão & Edema & Neutrófilo & Granulação & Fibrose & Monócitos & Somatória \\
\hline Cão 1 & 0 & 0 & -1 & 1 & 3 & 3 & 6 \\
\hline Cão 2 & -1 & 0 & -1 & 1 & 2 & 3 & 4 \\
\hline Cão 3 & 0 & -1 & -1 & 1 & 2 & 1 & 2 \\
\hline Cão 4 & 0 & -1 & 0 & 3 & 2 & 3 & 7 \\
\hline Cão 5 & 0 & -1 & -1 & 1 & 3 & 3 & 5 \\
\hline Cão 6 & -1 & 0 & -2 & 2 & 3 & 3 & 5 \\
\hline Cão 7 & 0 & 0 & -1 & 2 & 3 & 3 & 7 \\
\hline Cão 8 & 0 & 0 & -2 & 1 & 3 & 2 & 4 \\
\hline Total & -2 & -3 & -9 & 12 & 19 & 21 & Média: 5 \\
\hline
\end{tabular}

Em relação à proliferação vascular observou-se proliferação intensa em $75 \%$ das lâminas e moderada em apenas $25 \%$. $(\mathrm{p}<0,05)$.

Análise quantitativa e qualitativa do colágeno e tecido muscular presente no local enxertado está contida na tabela 4 .
Observa-se uma importante regeneração muscular, correspondente a $64 \%$ da área analisada. O restante é representado por colágeno, sendo o colágeno imaturo do tipo III a fração mais representativa.

TABELA 4 - Estudo Densitométrico do colágeno. Comparação do percentual de incorporação de fibras colágenas maduras (tipo I) e imaturas (tipo III) e percentual de tecido muscular presente

\begin{tabular}{lllll}
\hline Cão & $\begin{array}{l}\text { Colágeno Maduro (tipo } \\
\text { I) }\end{array}$ & $\begin{array}{l}\text { Colágeno Imaturo (tipo } \\
\text { III) }\end{array}$ & $\begin{array}{l}\text { Colágeno } \\
\text { Total }\end{array}$ & Músculo \\
\hline Cão 1 & 7.06 & 28.26 & 35.7 & 64,3 \\
Cão 2 & 7.5 & 24.26 & 31.76 & 68,27 \\
Cão 3 & 4.44 & 34.1 & 38.54 & 61,46 \\
Cão 4 & 9.21 & 31.56 & 41.46 & 58,54 \\
Cão 5 & 12.86 & 23.82 & 36.96 & 63,04 \\
Cão 6 & 6.3 & 20.22 & 26.52 & 73,48 \\
Cão 7 & 12.86 & 35.22 & 48.08 & 51,92 \\
Cão 8 & 7.90 & 28.64 & 36.68 & 63,32 \\
& & & & \\
\hline Média & 8.02 & 28.26 & 36.96 & 63,04 \\
\hline Desvio & 3.26 & 5.68 & 6.88 & 9,45 \\
Padrão & & & & \\
\hline \% & 37 & 20 & 18 & 15 \\
Desvio & & & & \\
Padrão & & & & \\
\hline
\end{tabular}




\section{Discussão}

A necessidade de encontrar-se um material ideal que apresente todas as características fundamentais da biocompatibilidade constitui o objetivo de vários estudos clínicos e experimentais.

A SIS tem demonstrado resultados superiores à outros materiais compostos por colágeno graças à sua estrutura tridimensional e a presença fatores de crescimento, proteínas estruturais, como as glicoproteínas e proteoglicanos. A combinação desses fatores promove a migração, interação célula-matriz extracelular, crescimento e diferenciação celular, sendo esses, os processos essenciais para a regeneração do tecido $^{8}$.

Estudos em ratos e cães demonstraram regeneração completa das 3 camadas da bexiga (mucosa, muscular e serosa) sem ocasionar a diminuição da capacidade vesical ou a retração do enxerto. A SID, quando usada para enxerto vesical promove a regeneração das 3 camadas vesicais dentro de um período aproximado de 1 mês. A regeneração de músculo liso garante a capacidade de contração e relaxamento de uma bexiga normal. Dessa forma, o funcionamento urodinâmico ocorre de forma satisfatória sem causar morbidades a curto prazo 9 .

Nosso primeiro estudo com SID na bexiga foi realizado com a utilização de submucosa autóloga de cães ${ }^{11}$. Os resultados foram muito semelhantes aos observados com a submucosa heteróloga de origem porcina, comprovando-se assim a ausência de rejeição. Isto vem de encontro a relatos da literatura que evidenciam a ausência de reação inflamatória do tipo Th1 que estaria relacionada à rejeição ${ }^{10}$.

Como no estudo anterior evidenciamos maior quantidade de fibras colágenas tipo III (imaturas). Talvez uma análise feita no $2^{\circ}$ ou $3^{\circ}$ mês de pós-operatório pudéssemos constatar maior quantidade de fibras colágenas tipo I (maduras). Semelhante ao estudo já publicado, verificamos ausência de reação inflamatória aguda e discreta presença de reação de corpo estranho, atribuída muito mais à sutura do que uma reação à membrana em $\mathrm{si}^{11}$.

O presente estudo evidenciou no $30^{\circ}$ dia de pósoperatório a ocorrência de grande quantidade de tecido muscular liso no local do implante. Em todos os animais verificou-se a total urotelização do enxerto e uma expressiva neovascularização. A quantificação de músculo liso no enxerto foi realizada no presente estudo, demonstrando que as fibras musculares lisas estiveram presentes em percentuais significativos ( $60 \%$ da área em média) o que difere do estudo anterior no qual realizou-se apenas uma análise qualitativa.

Sob a influência dos fatores de crescimento tais como fatores fibroblásticos (FGF-2), fatores vasculares endoteliais (VEGF), fatores de crescimento beta transformador (TGFß), que atuam como moléculas sinalizadoras ${ }^{3,6,12}$, as células de regeneração migram da bexiga primitiva para o local do enxerto. A cobertura completa da superfície mucosa do enxerto pelo urotélio começa como uma única camada que gradualmente se transforma em epitélio transicional com múltiplas camadas semelhantes à bexiga normal.
A angiogênese é fundamental para o suprimento vascular do tecido vesical em remodelação. Proliferação e migração de células endoteliais, induzidos por fatores quimiotáxicos presentes na matriz extracelular e nas células adjacentes, promovem a neoangiogênese ${ }^{13-23}$. São essas células endoteliais que vão originar os tubos vasculares, ramos e capilares propriamente ditos. Esse processo ocorre nas primeiras semanas (2-6 semanas) após o implante do enxerto.

O estudo criterioso dos campos de leitura microscópica demonstrou agrupamentos celulares corados presentes no enxerto, bem como a formação de neovasos sanguíneos. Essas células, que representam o mesênquima indiferenciado, são progenitoras de células endoteliais.

Há uma hipótese de que os miofibroblastos se diferenciam em células musculares lisas $^{2}$, porém essa teoria ainda não foi fundamentada no que se refere à SID implantada.

O presente estudo demonstrou que um retalho de submucosa de intestino porcino pode ser um excelente substrato para a regeneração vesical, quando implantado na bexiga de cães, permitindo assim um importante crescimento epitelial e vascular. O crescimento de um novo tecido contrátil sobre o molde de submucosa é preferível a uma cicatriz inerte, muitas vezes limitante no que diz respeito à contratilidade.

\section{Conclusão}

A submucosa de intestino heteróloga mostrou ser um bioenxerto capaz de induzir a neoangiogênese, a neoformação muscular e a deposição de colágeno necessária para a aumento e reparo vesical.

\section{Referências}

1. Portis A.J, Elbahnasy AM, Shalhav AL, Brewer A, Humphrey P, Mcdougall EM, Clayman R.V. Laparoscopic augmentation cystoplasty with different biodegradable grafts in an animal model. J Urol. 2000;164: 1405-11.

2. Pope JC, Davis MM., Smith JR, Walsh MJ, Ellison PK, Rink RC, Kropp BP. The ontogeny of canine small intestinal submucosa regenerated bladder. J Urol. 1997; 158: 1105-10.

3. Voytik-Harbin SL, Brightman AO, Kraine MR, Waisner B, Badylak SF. Identification of extractable growth factors from small intestinal submucosa. J Cell Biochem. 1997; 67: 478 - 91.

4. Abraham GA, Murray J, Billiat A. Evaluation of the porcine intestinal collagen layer as a biomterial. J Biomed Mater Res. 2000; 51 (3): 442-52.

5. Cayan S, Chermansky C, Schlote N, Nunes L, Dahiya R, Tanagho EA. The bladder acellular matrix graft in a rat chemical cystitis model: function and histological evaluation. J Urol. 2002; 168(2):798-804.

6. Hodde JP, Savaiano JK. Hyaluronic acid content of SIS. Second SIS Symposium, Orlando -Florida 1998; p.90.

7. Liang, HA, Record RD, Hodde JP, Badylak SF. Human microvascular endothelial cell adhesion to small intentinal submucosa. Second SIS Symposium, Orlando -Florida, 1998; p.91.

8. Kropp, BP, Eppley BL, Prevel CD, Rippy MK, Harruff MD, Badylak S F, ADAMS M C, RINK RC, KEATING MA. Experimental assessment of small intestinal submucosa as a bladder wall substitute. Urology. 1995, 46:396 - 400 . 
9. Grossklaus DJ, Shappel SB, Adams MC, Brock JW.III, Pope JC.IV. Small intestine submucosa as a urethral coverage layer. JUrol. 2001; 166(2): 636-9.

10. Allman AJ; Mcpherson TB; Badylak SF; Merrill LC; Bhaskar K; Sheehan C; Raeder RH; Metzger DW. Xenogeneic extracelular matrix grafts elicit a Th2-restricted immune response. Transplantation. 2001; 71(11):1631-40.

11. Greca FH, Biondo-Simões MLP, Santos EAA, Zanelatto-Gonçalves PC, Chin EWK, Ioshii SO. Retalho de submucosa de intestino delgado autólogo para aumento da capacidade da bexiga: estudo experimental em cães. Rev Col Bras Cir. 2002; 29(5):294-9.

12. Hodde JP, Record RD. Evidence of angiogenic activity in SIS Second SIS Symposium 1998; Orlando -Florida, p.38.

13. Cyan S, Chermansky C, Schlote N, Nunes L, Dahiya R, Tanagho EA. The bladder acellular matrix graft in a rat chemical cystitis model: function and histological evaluation. J Urol. 2002; 168(2):798-804.

14. Del Pizzo JJ, Jacobs SC, Bartlett ST, Sklar GN. The use of bladder for total transplant ureteral reconstruction. J Urol 1998; 159: 7502 .

15. Gloeckner DC. Mechanical and structural analyses of an acellular collagenous biomaterial: intestinal submucosa. Biomedical Engineering. Coral Gables, University of Miami 1998; 74.

16. Liatsikos EN, Dinlenc CZ, Kapoor R et al. Ureteral reconstruction: small intestine submucosa for the management of strictures and defects of the upper third of the ureter. J Urol. 2001;
165(5):1719-23.

17. Lindberg K, Badylak SF. Porcine small intestinal submucosa (SIS): a bioscaffold supporting in vitro primary human epidermal cell diferentiation and synthesis of basement membrane proteins. Burns. 2001; 27(3): 254-66.

18. Mcpherson TG, Badylak SF. Characterization of fibronectin derived from porcine small intestinal submucosa. Tissue Eng. 1998; 4:75-83.

19. O'Connor RC, Patel RV, Steinberg GD. Succcesful repair of a uretero-neobladder stricture using porcine small intestine submucosa. J Urol 2001; 165(6): 1995.

20. Olweny EO, Landman J, Andreoni C, Collyer W, Kerbl K, Onciu M, Välimaa T, Clayman RV. Evaluation of the use of a biodegradable ureteral stent after retrograde endopyelotomy in a porcine model. J Urol. 2002; 167: 2198-202.

21. Roeder, RA; Wolfe, J; Lianakis, N; Hinson, T; Geddes, LA; Obermiller, J. Compliance, elastic modulus, and burst pressure of small intestine submucosa (SIS), small-diameter vascular grafts. J Biomed Mat Res. 1999; 47(1):65-70.

22. .Roeder RA, Lantz GC, Geddes LA. Mechanical remodeling of small-intestine submucosa- diameter vascular grafts: a preliminary report. Biomed Instrum Technol. 2001; 35(2), 110-20.

23. Sofer M, Rore E, Forder DM, Denstedt JD. Ureteral segmental replacement using multilayer porcine small-intestinal submucosa. J Endourol. 2002; 16(1):27-31.

Conflito de interesse: nenhum

Fonte de financiamento: nenhuma

Recebimento: 12/08/2004

Revisão: 29/09/2004

Aprovação: 03/11/2004

\section{Como citar este artigo:}

Greca FH, Sousa Filho ZA, Silva APG, Leonel IS, Soccol AT, Feres AN, Longhi P. Utilização da submucosa de intestino delgado porcino como retalho para aumento da capacidade vesical em cães. Acta Cir Bras. [serial online] 2004 Nov-Dez;19(6). Disponível em URL: http://www.scielo.br/acb [também em CD-ROM]. 